\title{
30. SHORT-TERM SPECTRAL ANALYSIS OF DOWNHOLE LOGGING MEASUREMENTS FROM SITE 7041
}

\author{
C. J. Mwenifumbo ${ }^{2}$ and J. P. Blangy ${ }^{3}$
}

\begin{abstract}
Short-term spectral analysis was carried out on geochemical logging data from ODP Site 704. The FFT was used to compute the amplitude spectra of short-term overlapping segments to produce depth-period-amplitude spectrograms of the logging data. The spectrograms provided a means of evaluating the significance of the observed periodic components. The periodic components that were consistently present and prominent across a given record interval were considered to be significant. Changes in the spectrogram characteristics seem to reflect changes in either lithology, sedimentation rates, or hiatuses and may therefore provide useful information to aid in stratigraphic and paleoenvironmental studies. The dominant periodicity during the late Pleistocene and Brunhes Chron ( 0.97 to 0.47 Ma) was determined to be $>100,000 \mathrm{yr}$ whereas the upper Matuyama Chron was dominated by the 41,000 -yr periodicity. These periodicities suggest that the sedimentation patterns within the upper Matuyama Chron $(0.98-1.78 \mathrm{Ma})$ were influenced by the Milankovitch obliquity cycle and those within the latest Matuyama-Brunhes Chron $(<0.98 \mathrm{Ma})$ by the eccentricity cycle. The Brunhes/Matuyama boundary therefore represents a major discontinuity. Periodicities observed within the lower Matuyama and the upper Gauss Chron did not correlate with any of the periodicities within the Milankovitch frequency bands.
\end{abstract}

\section{INTRODUCTION}

Various spectral techniques have been used in analyzing deep-sea pelagic sediment records (oxygen isotope ratios, carbonate content, sea-surface temperatures, and abundances of the radiolarian Cycladophora davisiana) for periodicity related to orbital-induced paleoclimatic changes (Hays et al., 1976; Imbrie and Imbrie, 1980; Briskin and Harrell, 1980; Moore et al., 1982; Park and Herbert, 1987).

Pestiaux and Berger (1984) have reviewed a number of these techniques. The common spectral analysis approach is to take the fast Fourier transform (FFT) of a time or depth series. Periodicities of the prominent peaks in the amplitude or power spectrum are then analyzed. The drawback with this approach is that all of the time- or depth-varying detail within a given record is lost and it is often difficult to determine the significance of the various spectral peaks. To look at changes in periodicities with depth and thus study the time evolution of the spectral characteristic of a given record, a short-term data window is analyzed at a specific time and then progressively shifted with depth or time. This approach has not been extensively used previously in the spectral analysis of deepsea sediment records except for a brief discussion by Pestiaux and Berger (1984).

In the present study, downhole geochemical data are processed by successive overlapping of segments to produce a string of amplitude spectra that are then presented as a depth-period-amplitude spectrogram. This method of spectral analysis is analogous to the display of speech as sound spectrograms that represent a time-frequency-intensity display of short-time spectra (Oppenheim, 1970). The significance of the spectral peaks is qualitatively evaluated. Those

${ }^{1}$ Ciesielski, P. F., Kristoffersen, Y., et al., 1991. Proc. ODP, Sci. Results, 114: College Station, TX (Ocean Drilling Program).

2 Mineral Resources Division, Geological Survey of Canada, 601 Booth Street, Ottawa, Ontario, Canada K1A 0E8.

${ }^{3}$ Department of Geophysics, Stanford University, Stanford, CA (Present address: Unocal Science and Technology, 376 S. Valencia Avenue, Brea, CA 92621). that correlate over most of the record are taken to be significant and attempts are then made to relate them to periodicities that correspond to Milankovitch Earth orbital parameters of eccentricity, obliquity, and precession.

One of the major objectives in the present study is to look at changes in the spectrogram characteristics with depth. Changes in the characteristics of the spectra may provide valuable information that may be related to changes in sedimentation rates, lithology, diagenesis, and other post-depositional parameters.

\section{DESCRIPTION OF DATA}

Spectral analysis was carried out on downhole geochemical data from Ocean Drilling Program (ODP) Site 704 on the southern part of the Meteor Rise $\left(46^{\circ} 52.757^{\prime} \mathrm{S}, 07^{\circ} 25.250^{\prime} \mathrm{E}\right)$. Hole 704B was drilled to $671.7 \mathrm{~m}$ below seafloor (mbsf) at a water depth of $2532 \mathrm{~m}$. The geochemical logs run include the calcium $(\mathrm{Ca})$ elemental yield log and the lithology indicator ratio (LIR), the ratio of silicon elemental yield to the sum of silicon plus calcium elemental yields, $\mathrm{Si} /(\mathrm{Si}+\mathrm{Ca})$. The LIR is used as a semiquantitative indicator of the relative abundances of quartz and biogenic silica to calcite assuming the absence of clays. These data are presented in Figure 1.

Periodicities related to climatic changes are expected in the geochemical logs because climatic changes affect productivity and the influx of detrital material. Site 704 is within a zone that experienced mixed biosiliceous and calcareous productivity throughout the Oligocene-Quaternary period, with little influx of terrigenous sediment by currents or ice rafting. The sedimentary sequence consists of varying amounts of two endmember components: (1) calcareous oozes and chalks composed mainly of foraminifers and calcareous nannofossils and (2) siliceous oozes composed mainly of diatoms with minor amounts of radiolarians and silicoflagellates (Ciesielski, Kristoffersen, et al., 1988). In general, the upper Quaternary sediment sequence shows distinct cycles in the amount of calcium (calcium carbonate) that correlate with dark and light cycles in sediment color. The calcium minima correspond to the darker parts of the color cycles and most maxima correspond to higher carbonate content. One of the objectives of 


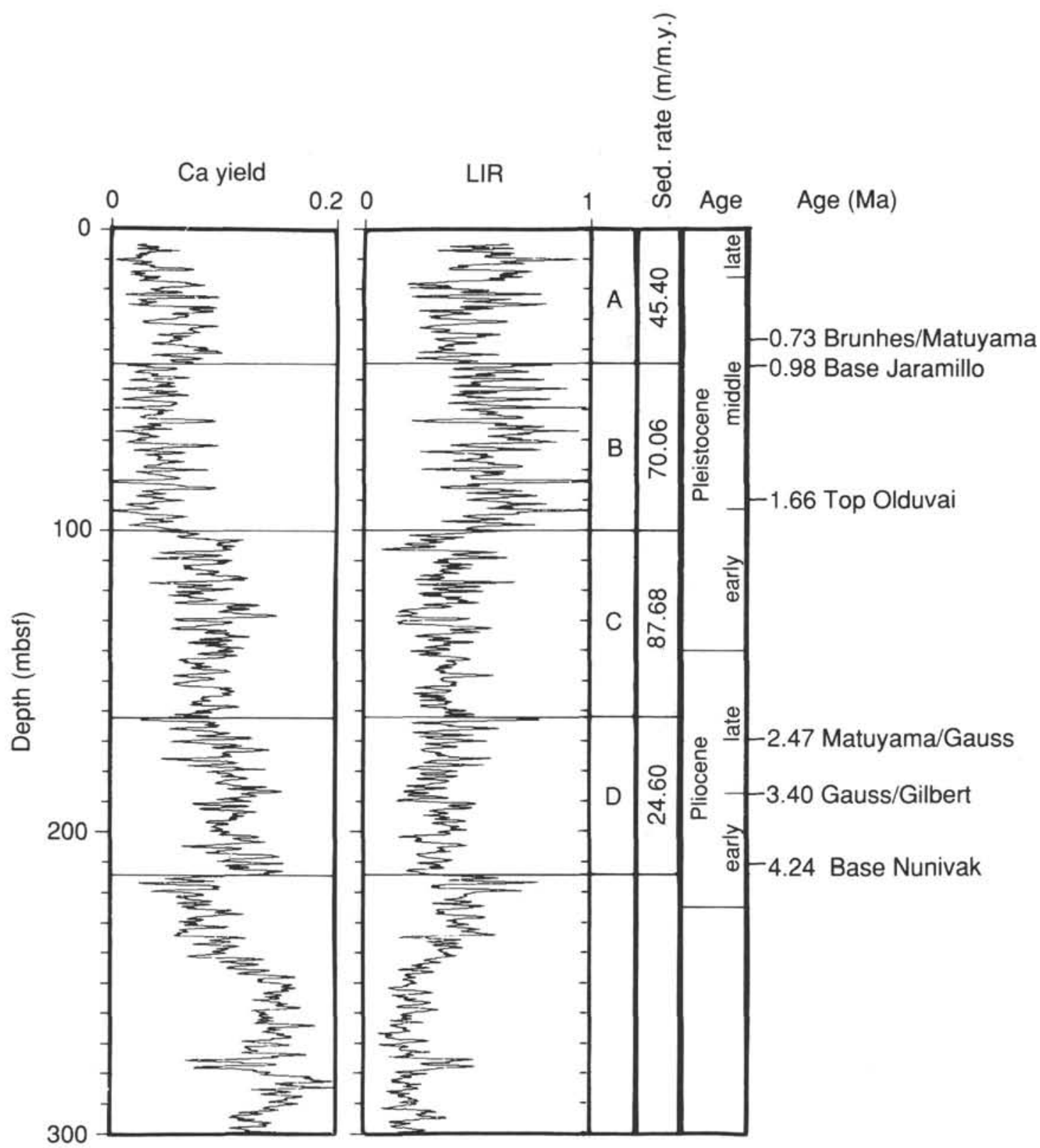

Figure 1. Calcium (Ca) elemental yield and the lithology indicator ratio ( $\mathrm{LIR}=\mathrm{Si} /[\mathrm{Si}+\mathrm{Ca}])$ from 0 to $300 \mathrm{mbsf}$ at $\mathrm{Hole}$ 704B. The LIR is used as an indicator of the relative abundances of quartz and biogenic silica to calcite. Also given are the sedimentation rates and ages. The logging data were divided into the four intervals A, B, C, and D for spectral analysis. These intervals are indicated by solid lines across the logs and do not represent stratigraphic units.

the spectral analysis was to accurately determine the carbonate-silica cycles in these sediments and attempt to correlate the observed frequency peaks with periods that correspond to the Milankovitch Earth orbital parameters of eccentricity, obliquity, and precession.

Although Hole 704B was drilled to $671.7 \mathrm{mbsf}$, only data from 0 to $214 \mathrm{mbsf}$-spanning a time interval of approximately 4.50 Ma-were analyzed. These data were sampled at a uniform depth interval of $0.15 \mathrm{~m}$. The data were divided into four intervals for spectral analysis, extending from the early Pliocene to the late Pleistocene. The differentiation of these intervals was based on changes in Ca yield and LIR and on sedimentation rates (Fig. 1). Interval A occurs mostly in the Brunhes and part of the upper Matuyama Chrons to the base of the Jaramillo Subchron and extends from 0.41 to $0.97 \mathrm{Ma}$. The Matuyama is divided into two intervals: interval B (0.98-1.78 Ma), which extends from the base of Jaramillo to below the Olduvai Subchron, and interval C (1.78-2.41 Ma), which extends from below the Olduvai Subchron to just above the Matuyama/Gauss boundary. The last interval D (2.42-4.37 Ma) occurs from just above the Matuyama/Gauss boundary to just below the base of the Nunivak Subchron of the Gilbert Chron. The sedimentation rates of $45.40,70.06,87.68$, and $24.60 \mathrm{~m} / \mathrm{m}$.y. for intervals A, B, C, D, respectively, are assumed to be uniform within each interval. Magnetic reversal and biostratigraphic datums were used to determine sedimentation rates and ages (Hailwood and Clement, this volume; Ciesielski, Kristoffersen, et al., 1988). 


\section{DATA MANIPULATION BEFORE FOURIER TRANSFORMATION}

One of the procedures in processing this type of data before spectral analysis is to transform the depth data into time using known sedimentation rates. This procedure of mapping depth into time yields values at irregular intervals, and generally the next step is to interpolate the data into a constant time interval prior to applying the FFT. We have chosen not to convert depth into time in our analysis because interpolation can introduce uncertainties in the signal that may generate spurious frequencies in the spectrum. Although there are spectral analysis techniques that do not require data at equal sample intervals (e.g., Periodic Regression with Cyclic Descent; Briskin and Harrell, 1980), the major problem is still that the depth-time mapping function is usually not reliable because of the inaccuracies in the sedimentation rates (Morley and Shackleton, 1984; Schiffelbein and Dorman, 1986; Park and Herbert, 1987). We thus analyze the FFT-generated amplitude spectra of discrete depth series of $\mathrm{Ca}$ and LIR.

Before performing the FFT, the data have to be detrended in order that the signal be "stationary" and a window function also has to be applied to the residual data set to reduce spectral leakage due to a finite length signal.

\section{Detrending}

When calculating a spectrum, one of the basic assumptions made is that the data set is stationary at least over the interval being analyzed (i.e., there is no long-term drift or trend). A third-order polynomial regression fit to the data was computed, and this function was then subtracted from the data to obtain the residual that contains information on short-term variations that are effectively stationary. This residual, with a mean that is approximately zero, forms the input data set for Fourier analysis. Figure 2 shows an example of how this
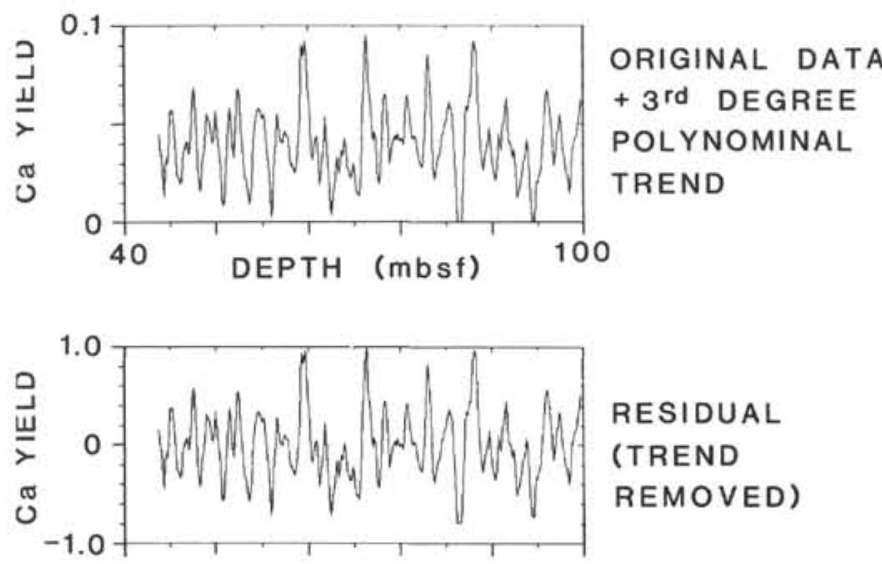

RESIDUAL (TREND REMOVED)

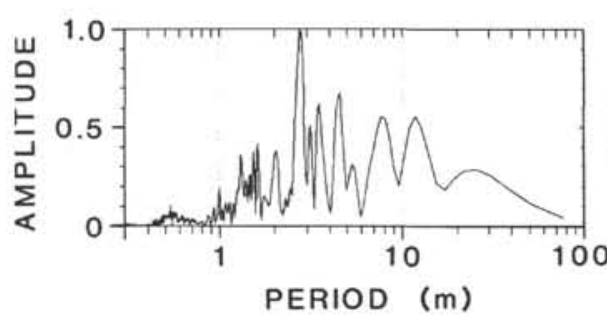

AMPLITUDE SPECTRUM

Figure 2. A third-order polynomial regression fit is applied to the log data in processing to generate the residual that is effectively stationary and has a mean that is approximately zero. The spectrum is plotted as linear amplitude vs. the logarithm of the period in meters. procedure was implemented. All the data presented in this paper have been analyzed in this fashion.

\section{Choice of Data Windows}

The main problem with short-term spectral analysis is that the finite length of the signal causes spectral leakage. To reduce the leakage in the discrete Fourier transform (DFT) it is necessary to apply a weighting function, or window, to the data before transformation. A number of weighting functions have been used in spectral analysis (Welch, 1967; Harris, 1978; Park et al., 1987), and in the present analysis the Parzen and Welch windows were considered and qualitatively evaluated. There was no noticeable difference in the amplitude spectra when either a Parzen or Welch window was used. The present data were analyzed using the Welch window (Welch, 1967).

\section{SPECTRAL ANALYSIS}

The FFT was used to derive the amplitude spectra of short-term overlapping segments of downhole geochemical data to produce a depth-period-amplitude spectrogram. Successive overlapping segments for a $75 \%$ overlap are illustrated in Figure 3. In the computation of the short-term spectra, the length of segment, spacing of the spectral estimates, and the amount of overlap required have to be considered.

\section{Choice of Segment Length}

The choice of the record length of the segment depends primarily on the frequency content of the signal to be analyzed. A long record length will encompass a wider range of frequencies, but will be less sensitive to local variations. A short record length will pose some restrictions on the low frequency content of the signal that can be perceived but will be sensitive to localized trends due to variations in sedimentation rates and lithology. A segment length covering 128 points, equivalent to $19.05 \mathrm{~m}$ (sample depth interval of 0.15 $\mathrm{m}$ ), was chosen. For sedimentation rates between 60 and 100 $\mathrm{m} / \mathrm{m}$.y., the periodicity analyzed was of the order of 158,000 to $95,000 \mathrm{yr}$, respectively. This window length is, however, too short to detect periodicity that corresponds to the $410,000-y r$ Milankovitch eccentricity cycle. Longer segments were attempted, but the variations in sedimentation rates caused interferences of frequencies or periods that pose problems in frequency discrimination and the evaluation of the significance of the various observed spectral peaks.

\section{Spacing of the Spectral Estimates}

Given a segment of data of length $L$, the DFT yields an amplitude spectrum with estimates spaced $1 / L$ units apart. If more finely spaced estimates are desired, zeros are added to the sequence of data before taking the Fourier transform (Welch, 1967). Figure 4 shows the effects of zero padding the

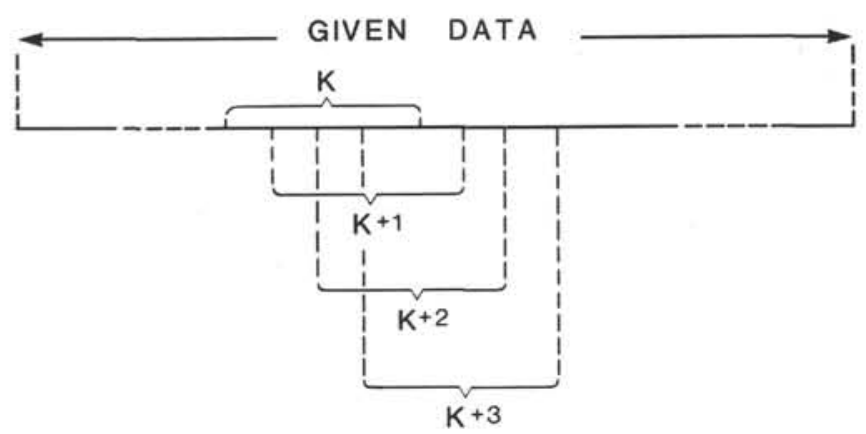

Figure 3. Successive overlapping segments for a $75 \%$ overlap. 


\section{DEPTH (mbsf)}

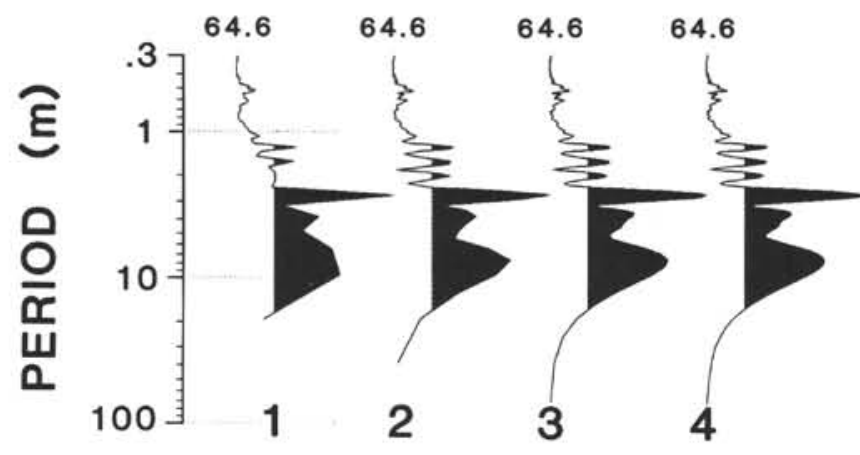

Figure 4. Amplitude spectra showing the effects of zero padding the data to increase the sampling in the wave number ("frequency") domain. The amplitude spectra are displayed on a linear-logarithmic plot with a linear amplitude plotted against the logarithm of the period. Amplitudes greater than $25 \%$ of the maximum peak amplitude are shaded. The amplitude spectra of a 128-point segment without zero padding and with zero padding to 256,512 , and 1024 points are shown in spectra $1,2,3$, and 4 , respectively. Note the increase in resolution of the peak between 7 and $10 \mathrm{~m}$ as the zero padding is increased to 1024 points.

data to increase the sampling in the wave number ("frequency") domain. The wave number (cycles/m) is converted into the period in meters and the amplitude spectra are displayed on a linear-logarithmic plot with a linear amplitude plotted against the logarithm of the period. Amplitudes greater than $25 \%$ of the maximum peak amplitude are shaded to highlight some of the prominent peaks. The amplitude spectrum for the 128 -point segment without zero padding is shown in Figure 4 as spectrum 1 . The amplitude spectra of the 128 data points with zero padding to 256,512 , and 1024 points are shown in spectra 2,3 , and 4, respectively. With a sample depth interval of $0.15 \mathrm{~m}$, the sample rate in the wave number domain thus becomes approximately $0.026,0.013$, and 0.007 cycles $/ \mathrm{m}$ instead of 0.052 cycles $/ \mathrm{m}$. It is clear from Figure 4 that an increase in the sample rate improves the peak resolution. For instance, a poorly defined broad spectral peak between 7 and $10 \mathrm{~m}$ for the 128 points without zero padding (spectrum 1) is clearly resolved when the data are zero padded to 1024 points (spectrum 4). All the data have been analyzed with the segment length zero padded to 1024 points, thus giving spectral estimates at intervals of 0.007 cycles $/ \mathrm{m}$.

\section{Overlap}

The depth-period-amplitude spectrograms shown for the Ca yield log from 44.60 to 102.05 mbsf in Figure 5 illustrate the effects of the amount of overlap on the spectrograms. The total record length is 384 points and the segment length is 128 points. For a $0 \%$ overlap there are only 3 spectra. There are 5 , 9 , and 17 spectra for $50 \%, 75 \%$, and $87.25 \%$ overlaps, respectively. It is clear that a higher degree of overlap shows changes in the spectra with depth better than the zero-overlap spectra and also makes it easier to determine the prominent peaks over the given depth interval (dominant peaks that persist over the entire depth-period-amplitude spectrogram are considered to be significant). The spectrum for the entire record length is given in Figure 2. A number of prominent peaks is observed at periods between 2 and $20 \mathrm{~m}$. The depth-period-amplitude spectrogram, however, shows that only those peaks with a period of about $3 \mathrm{~m}$ are significant because they are observed across the entire record length. Al data analyzed and presented in the following sections were processed with a segment length of 128 points and an $87.25 \%$ overlap equivalent to a 16-point shift for each successive spectrum.

\section{RESULTS}

\section{Interval A-Middle to Late Pleistocene (Brunhes Chron-Base Jaramillo Subchron, 0-44.5 mbsf = 0-0.98 Ma)}

The middle to late Pleistocene Brunhes Chron to the base of the Jaramillo Subchron spans the time interval from 0 to $0.98 \mathrm{Ma}(0-44.5 \mathrm{mbsf})$. The geochemical log data indicate that the base of the Jaramillo Subchron at approximately 44.27 mbsf is a major discontinuity, with higher mean $\mathrm{Ca}$ yield values in and above the Jaramillo Subchron than in the underlying Matuyama. The percent $\mathrm{CaCO}_{3}$ data also indicate a higher mean carbonate content within the Brunhes through Jaramillo than in the Matuyama and broadly correlate with the $\mathrm{Ca}$ yield data (Froelich et al., this volume). There is no indication of a change in lithology from core data at the base of the Jaramillo. Figure 6 shows the depth-period-amplitude spectrogram for the $\mathrm{Ca}$ yield $\log$ from 17.0 to $72 \mathrm{mbsf}$, straddling the Brunhes/Matuyama boundary. There is a marked change in the spectral characteristic of the signal at the base of the Jaramillo Subchron. The periodicity of the dominant and persistent peak within the Brunhes ranges from 5.69 to $9.60 \mathrm{~m}$, equivalent to $126,000-213,000 \mathrm{yr}$ (average periodicity of $169,000 \mathrm{yr}$ with the period apparently increasing with depth). The eccentricity terms in the Milankovitch cycles range from 95 to $136,000 \mathrm{yr}$, and it appears that the periodicities observed in the geochemical logging data within the Brunhes to base of the Jaramillo are generally equal to or greater than the 95 - to $136,000-y r$ Milankovitch cycles. Further study of this interval is needed because the substantial changes noted in the sediment-accumulation rate (Froelich et al., this volume) were not taken into account here.

\section{Interval B-Early Pleistocene (Upper Matuyama Chron, 44.50-100.55 mbsf $=0.98-1.78 \mathrm{Ma}$ )}

The depth-period-amplitude spectrograms for the $\mathrm{Ca}$ yield and LIR logs in interval B are presented in Figures 7 and 8 . The spectrograms for the two data sets are similar. All spectra show a dominant peak across the entire depth interval with a periodicity of approximately $2.69-3.01 \mathrm{~m}$ (equivalent to $41,000-46,000 \mathrm{yr}$ ). The dominant $100,000-\mathrm{yr}$ period observed within the Brunhes is almost nonexistent or fairly weak in the upper Matuyama interval B. The periods for the dominant peak of all the spectra are given in Table 1 . With a constant sedimentation rate estimated at 56.05 $\mathrm{m} / \mathrm{m} . \mathrm{y}$., this peak varies between 38,360 and $42,800 \mathrm{yr}$ $(2.4-3.0 \mathrm{~m})$ with an average period of $40,500 \mathrm{yr}$, which corresponds to the 41,000-yr Milankovitch obliquity cycle. Variations in periodicity probably reflect changes in sedimentation rates and/or diagenesis if we assume that the geochemical data set is an accurate representation of variations in the carbonate-silica content.

The period is plotted against the mean depth of the spectra in Figure 9. Changes in the period seen at approximately 60 and 80 mbsf ( 1.22 and $1.52 \mathrm{Ma})$ are reflected as changes in the characteristics of the spectrogram. The amplitude spectrum for the entire record from 44.6 to $99.7 \mathrm{mbsf}(0.985-1.77 \mathrm{Ma})$ is presented in Figure 2. The dominant peak is at $2.74 \mathrm{~m}(38,900$ $\mathrm{yr})$. There are, however, other prominent peaks at periods of $3.5,4.5,7.7$, and $11.8 \mathrm{~m}$, equivalent to $49,700,63,900,109,400$, and $167,800 \mathrm{yr}$, respectively. It is difficult to evaluate the 


\section{DEPTH (mbsf)}
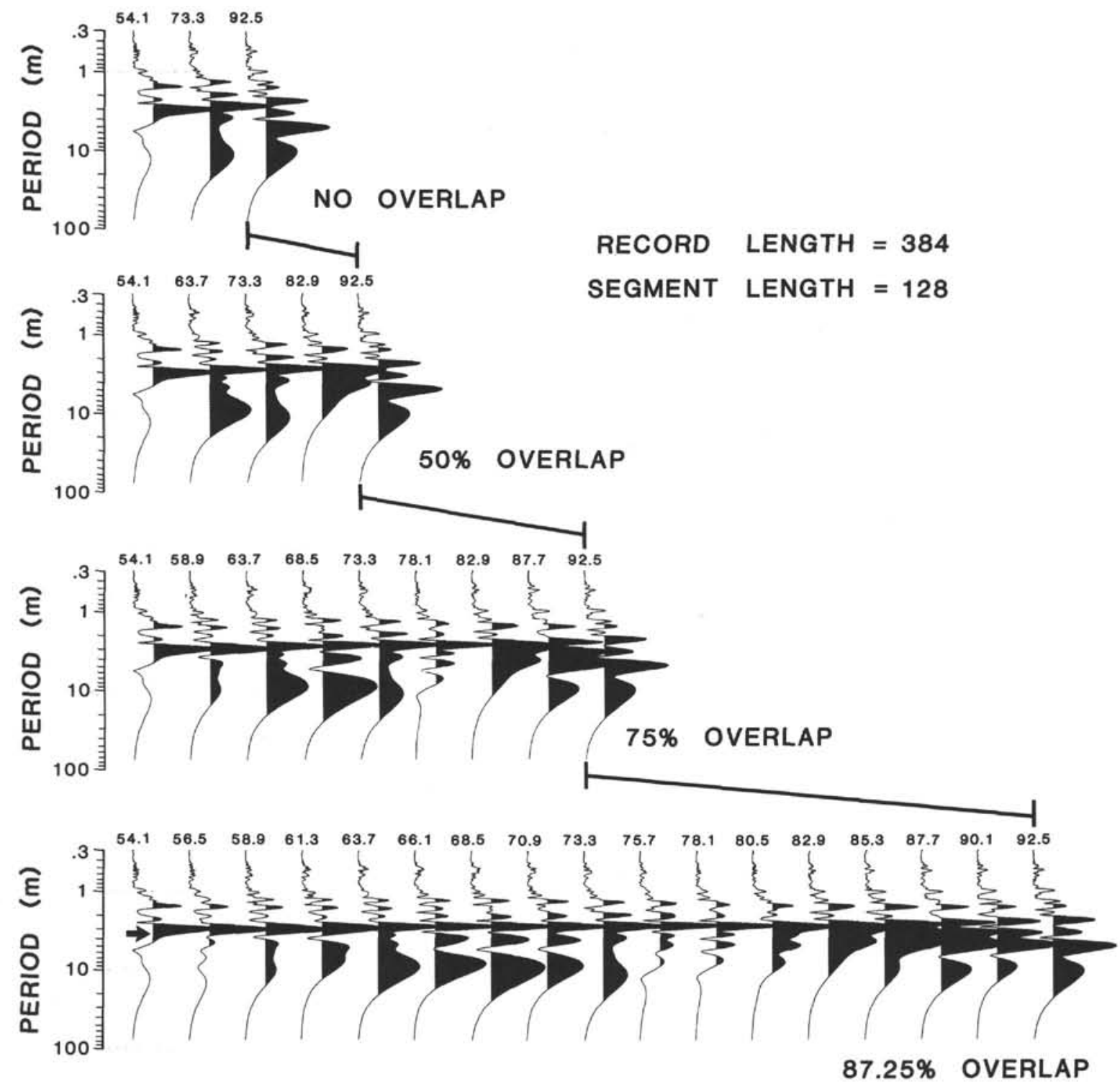

Figure 5. Depth-period-amplitude spectrogram of the Ca yield log data from 44.60 to 102.05 mbsf ( $0.985-1.797 \mathrm{Ma})$ (interval B), illustrating the effects of the degree of overlap on the spectrograms. As the overlap is increased the changes in the spectra with depth are better resolved and the most significant spectral peaks are clearly indicated.

relative significance of each of these other peaks from the spectrum of the entire record, but the depth-period-amplitude spectrogram clearly shows that none of them persists across the entire data series in interval B. These periods can be seen only in the spectra between 61 and 73 mbsf (1.23-1.42 Ma) and between 80 and 90 mbsf (1.52-1.67 Ma). Because of their lack of persistence these periods are not considered significant.

\section{Interval C (Lower Matuyama Chron, 100.55-162.80 mbsf $=1.78-2.41 \mathrm{Ma})$}

The depth-period-amplitude spectrograms for interval $\mathrm{C}$ are presented in Figure 10. The sedimentation rates within this interval averaged $87.68 \mathrm{~m} / \mathrm{m}$.y. Based on a number of changes in the characteristics of the spectra across this interval, interval $\mathrm{C}$ may be divided into three units: unit 1 from 110.1 to
119.7 mbsf (1.87-1.97 Ma), unit 2 from 119.7 to $134 \mathrm{mbsf}$ (1.97-2.12 Ma), and unit 3 from 134.1 to $158.1 \mathrm{mbsf}(2.12-2.36$ Ma). Unit 1 shows two significant peaks with large amplitudes concentrated at about 2.5 to $3.1 \mathrm{~m}(26,000-32,300 \mathrm{yr})$ and 4.65 to $5.3 \mathrm{~m}(48,400-55,200 \mathrm{yr})$. Of these two, the latter is more significant, but it disappears in unit 2 . The former period persists into unit 2 . The dominant and consistent spectral peak in unit 3 has a period ranging between 5.7 and $7.0 \mathrm{~m}(57,000$ $70,000 \mathrm{yr}$ ). None of the observed periodicities within interval $\mathrm{C}$ can be related to Milankovitch cycles.

Although there is no correlation between the Milankovitch cycles and the observed cyclicity of the sediment column in this interval, changes in the spectral signal characteristics may provide information on the changes in lithology, sedimentation rates, and/or post-depositional diagenetic parameters 


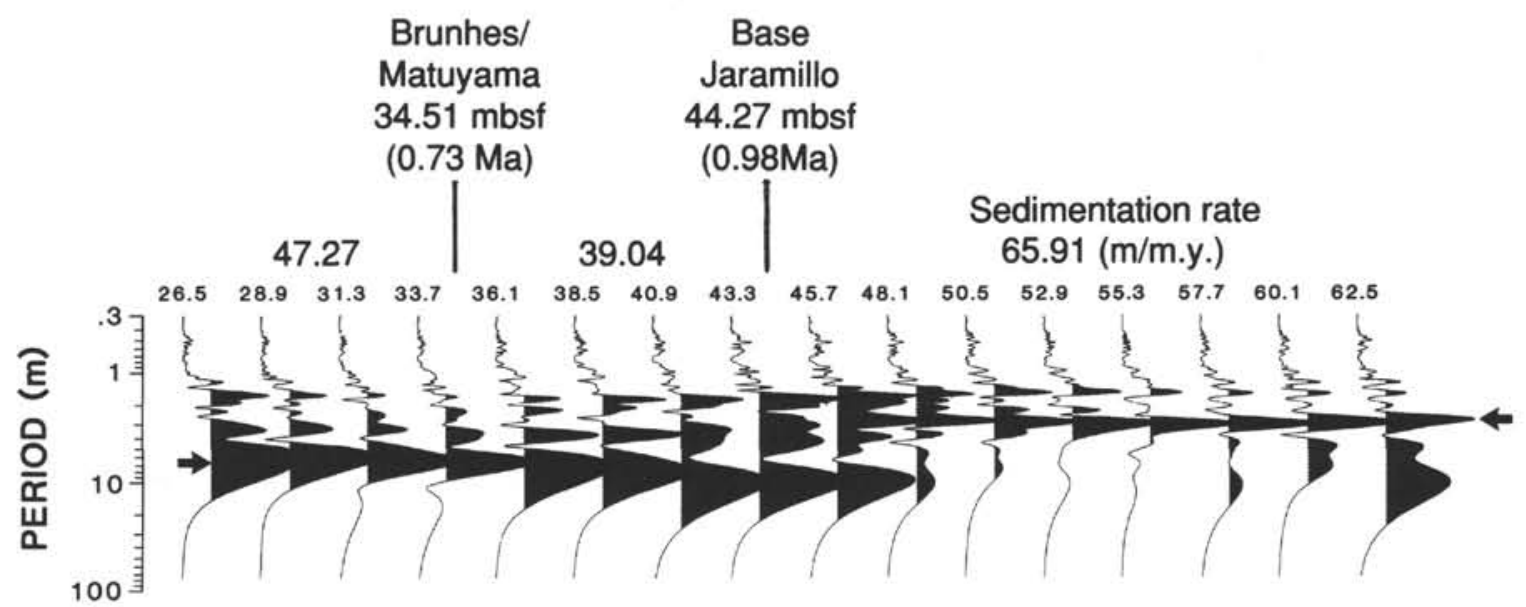

Figure 6. Depth-period-amplitude spectrogram of the Ca yield log data from 17.0 to $72 \mathrm{mbsf}$, straddling the lower Jaramillo Subchron boundary at approximately $44.27 \mathrm{mbsf}(0.98 \mathrm{Ma})$. There is a marked change in the spectral characteristic of the signal at the basal Jaramillo Subchron, and the geochemical log data also indicate a major discontinuity at this boundary, with higher mean Ca yield values in the Brunhes than in the Matuyama. Periodicity within the Brunhes to basal Jaramillo Subchron is $>100,000 \mathrm{yr}$, and that within the upper Matuyama is about $41,000 \mathrm{yr}$, equivalent to the Milankovitch eccentricity and obliquity cycles, respectively.

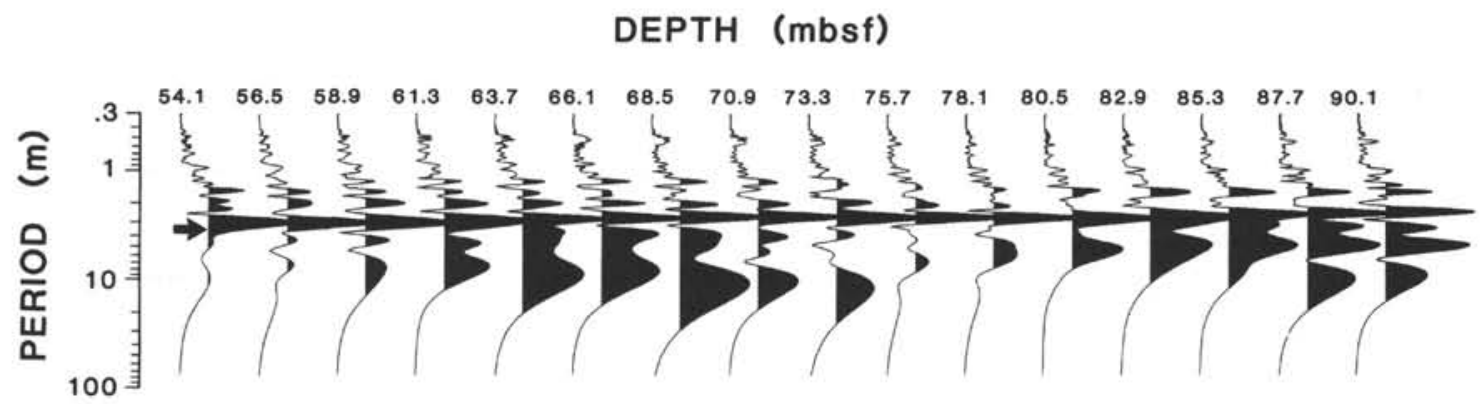

Figure 7. Depth-period-amplitude spectrogram of the Ca yield log data for interval B (0.98-1.78 Ma). The spectra show a dominant and persistent peak across the entire depth interval, with a periodicity of approximately $3 \mathrm{~m}$ (equivalent to $41,000 \mathrm{yr}$ ). This period corresponds to the 41,000-yr Milankovitch obliquity cycle.

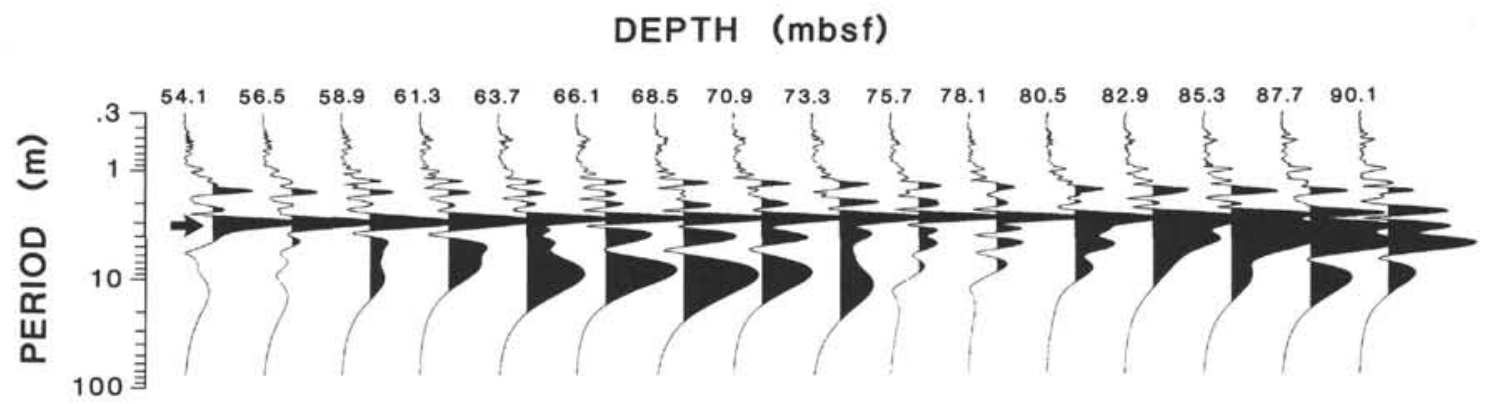

Figure 8. Depth-period-amplitude spectrogram of the LIR log data for interval B. The spectra show a dominant and persistent peak across the entire depth interval, with a periodicity of 3.69 to $3.01 \mathrm{~m}$ (equivalent to $41,000-46,000 \mathrm{yr}$ ). This spectrogram is similar to that of the Ca yield log data given in Figure 7.

such as compaction and carbonate dissolution. For instance, the Ca yield log shows above-average values between 125 and 132 mbsf (2.03-2.10 Ma), suggesting higher carbonate content and lower silica content (see the LIR log). The location of this change in lithology is reflected in a change in the spectra. Sedimentation rates determined from palaeomagnetic and biostratigraphic datums are quite variable in this interval (Hailwood and Clement, this volume). The palaeomagnetic datums provide the best estimates of the sedimentation rate, and these data indicate a slight change in sedimentation rate at approximately $130 \mathrm{mbsf}$, which may explain the change in the spectral signal within unit 2 .

\section{Interval D (Earliest Matuyama-Latest Gilbert Chron, 163.85-211.7 mbsf $=2.423-4.371 \mathrm{Ma}$ )}

The average sedimentation rate is $24.6 \mathrm{~m} / \mathrm{m}$.y. in interval D. The depth-period-amplitude spectrogram of the $\mathrm{Ca}$ yield data set for interval $\mathrm{D}$ is presented in Figure 11. The dominant 
Table 1. Dominant spectral peak location and period for the upper Matuyama interval B (44.6-99.65 mbsf, sedimentation rate $=64.49 \mathrm{~m} / \mathrm{m} . y$.$) , calcium yield, and LIR logging data.$

\begin{tabular}{|c|c|c|c|c|c|c|}
\hline \multirow[b]{2}{*}{$\begin{array}{l}\text { Age of depth } \\
\text { interval (Ma) }\end{array}$} & \multirow[b]{2}{*}{$\begin{array}{l}\text { Depth interval } \\
\text { (mbsf) }\end{array}$} & \multirow[b]{2}{*}{$\begin{array}{l}\text { Mean depth } \\
\text { (mbsf) }\end{array}$} & \multicolumn{2}{|c|}{ Calcium yield } & \multicolumn{2}{|c|}{ LIR } \\
\hline & & & $\begin{array}{l}\text { Spectral } \\
\text { peak } \\
\text { location } \\
\text { (m) }\end{array}$ & $\begin{array}{c}\text { Period } \\
(1000 \mathrm{yr})\end{array}$ & $\begin{array}{l}\text { Spectral } \\
\text { peak } \\
\text { location } \\
(\mathrm{m})\end{array}$ & $\begin{array}{c}\text { Period } \\
1000 \mathrm{yr})\end{array}$ \\
\hline $0.985-1.274$ & $44.60-63.65$ & 54.12 & 2.95 & 44.76 & 2.95 & 44.76 \\
\hline $1.021-1.310$ & $47.00-66.05$ & 56.52 & 3.01 & 45.67 & 3.01 & 45.67 \\
\hline $1.057-1.347$ & $49.40-68.45$ & 58.92 & 3.01 & 45.67 & 3.01 & 45.67 \\
\hline $1.094-1.383$ & $51.80-70.85$ & 61.32 & 2.90 & 44.00 & 2.90 & 44.00 \\
\hline $1.131-1.420$ & $54.20-73.25$ & 63.72 & 2.79 & 42.33 & 2.79 & 42.33 \\
\hline $1.167-1.450$ & $56.60-75.65$ & 66.12 & 2.74 & 41.57 & 2.74 & 41.57 \\
\hline $1.203-1.493$ & $59.00-78.05$ & 68.52 & 2.74 & 41.57 & 2.65 & 40.20 \\
\hline $1.240-1.529$ & $61.40-80.45$ & 70.92 & 2.74 & 41.57 & 2.65 & 40.20 \\
\hline $1.276-1.565$ & $63.80-82.85$ & 73.32 & 2.69 & 40.81 & 2.69 & 40.81 \\
\hline $1.313-1.602$ & $66.20-85.25$ & 75.72 & 2.69 & 40.81 & 2.69 & 40.81 \\
\hline $1.349-1.638$ & $68.60-87.65$ & 78.12 & 2.69 & 40.81 & 2.69 & 40.81 \\
\hline $1.381-1.670$ & $71.00-90.05$ & 80.52 & 2.74 & 40.85 & 2.74 & 40.85 \\
\hline $1.385-1.694$ & $73.40-92.45$ & 82.92 & 2.79 & 45.23 & 2.65 & 42.96 \\
\hline $1.458-1.719$ & $75.80-94.85$ & 85.32 & 2.60 & 35.62 & 2.52 & 34.53 \\
\hline $1.495-1.743$ & $78.20-97.25$ & 87.72 & 2.52 & 32.81 & 2.48 & 32.29 \\
\hline $1.531-1.768$ & $80.60-99.65$ & 90.12 & 2.44 & 30.36 & 2.44 & 30.36 \\
\hline
\end{tabular}

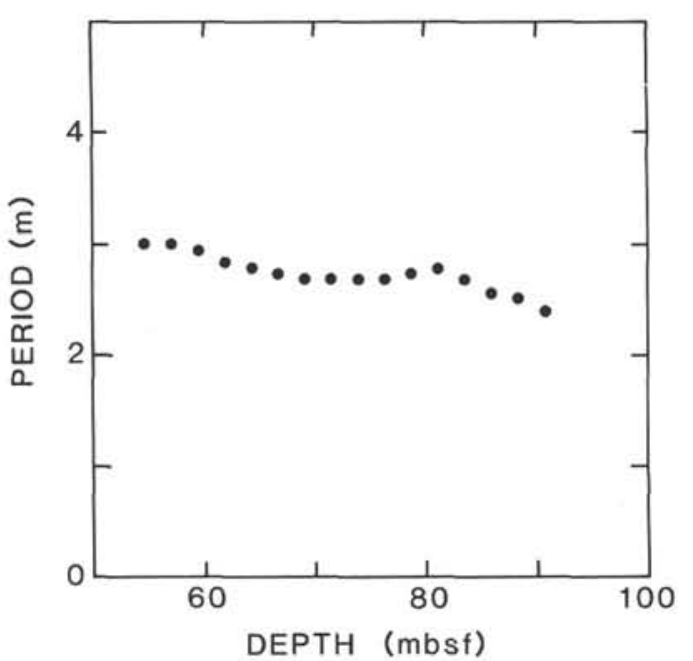

Figure 9. Period vs. the mean depth of the spectra from the Ca yield data in interval B. The location of noticeable changes in the period at approximately $60(1.219 \mathrm{Ma})$ and $80 \mathrm{mbsf}(1.522 \mathrm{Ma})$ is indicated as changes in the characteristics of the spectrogram.

spectral peak, which is fairly consistent across the entire interval, has a period ranging from 5.3 to $7.3 \mathrm{~m}(215,800$ to $297,200 \mathrm{yr}$; Table 2). None of the observed periodicities can be related to Milankovitch periodicities. The periodicities may, however, be produced by the mixing of the eccentricity frequency bands between 123,000 and $410,000 \mathrm{yr}$.

\section{DISCUSSION AND CONCLUSIONS}

The periodicity in carbonate-silica alternations within the Pleistocene at Site 704 reflects glacial and interglacial periods (Hodell et al., 1989). During glaciation, the productivity of siliceous microfossils (diatoms and radiolarians) increased and the carbonate content of the sediments decreased. Higher productivity of the carbonate-secreting plankton (foraminifers and calcareous nannofossils) occurred during the interglacial periods.

The dominant periodicity during the late Pleistocene latest Matuyama-Brunhes Chron (0.97-0.41 Ma) was 100,000 yr. This prominent period disappears in the upper Matuyama interval B. Periodicities detected in the Matuyama interval B are about $41,000-46,000 \mathrm{yr}$. The shift in the dominant periodicity from $\sim 41,000$ to $100,000 \mathrm{yr}$ near the base of the Jaramillo Subchron is very pronounced, and analyses of oxygen isotope records from the North Atlantic Oceans (Shackleton and Opdyke, 1976; Pisias and Moore, 1981; Ruddiman et al., 1986) show a similar change in periodicity near this boundary. This observation suggests that the oceans of the Northern and Southern hemispheres were responding similarly to the orbitally induced climatic changes. There are difficulties, however, in explaining this distinct change in periodicity because the nature of the variations in the Earth orbital parameters has changed little over the past $2 \mathrm{Ma}$ (Pisias and Moore, 1981; Ruddiman et al., 1986). A number of possible causes for a suggested nonlinear response of the climatic system to orbital forcing are discussed in Ruddiman et al. (1986).

None of the observed periodicities within lower Matuyama interval $\mathrm{C}$ show any significant periodicities that correspond to the Milankovitch frequency bands. The short-term spectral analysis of the data, however, shows that the changes in the spectral characteristic of the Ca yield and LIR may reveal local variations in sedimentation rates, lithology, and other postdepositional changes. There are three major factors that govern the carbonate content of a sediment (Volat et al., 1980): (1) the productivity of calcareous plankton, (2) the degree of carbonate dissolution, and (3) the amount of noncarbonate material, both detrital and biogenic. All three factors seem to contribute to the periodicity observed within this sediment column. Periodicity is related mainly to alternating deposition of carbonate and opal and thus reflects dilution signals on top of one another (Froelich et al., this volume). Diagenetic alteration to the sediments after 


\section{DEPTH (mbsf)}

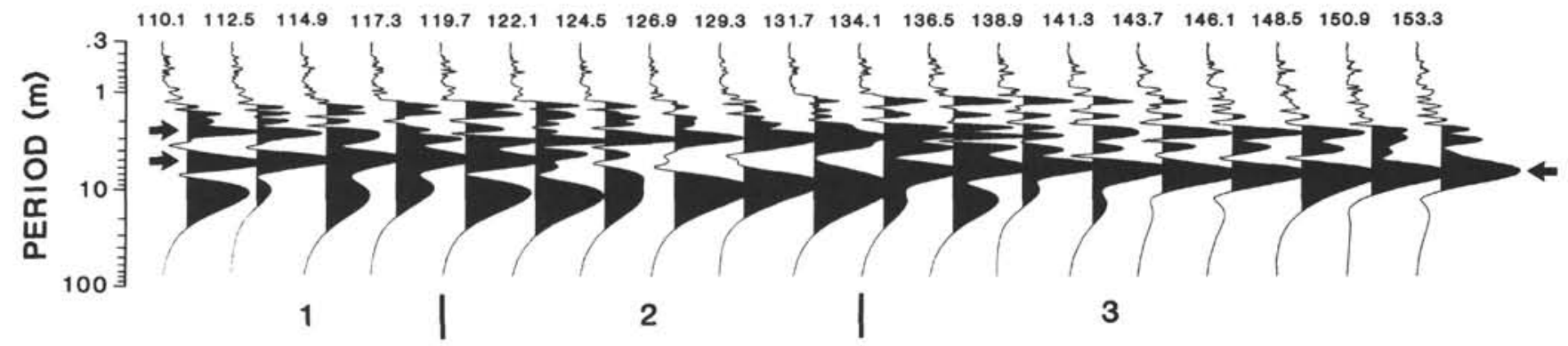

Figure 10. Depth-period-amplitude spectrogram of Ca yield data for the lower Matuyama interval C. Sedimentation rates within the interval average $87.68 \mathrm{~m} / \mathrm{m}$.y. Interval $\mathrm{C}$ may be divided into three units based on changes in the spectra.

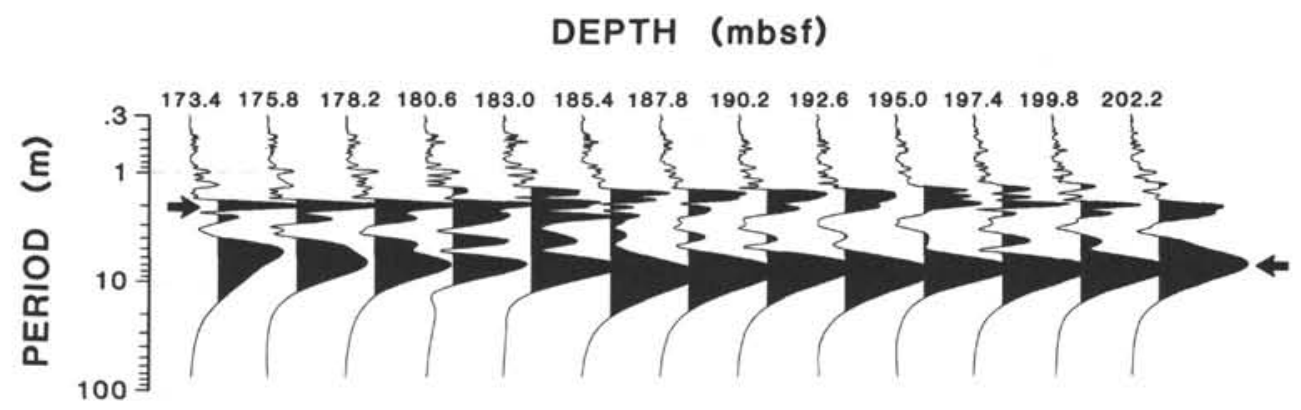

Figure 11. Depth-period-amplitude spectrogram of the Ca yield data for the Gauss to upper Gilbert Chron interval $\mathrm{D}$. The dominant spectral peak, which is fairly consistent across the entire interval, has a period ranging from 5.3 to $8.53 \mathrm{~m}(227,000$ to $371,000 \mathrm{yr})$.

Table 2. Dominant spectral peak location and period for Gauss Chron interval D (163.85-211.70 mbsf, sedimentation rate $=\mathbf{2 4 . 6}$ $\mathrm{m} / \mathrm{m} . \mathbf{y}$.) and calcium yield data.

\begin{tabular}{|c|c|c|c|c|}
\hline \multirow[b]{2}{*}{$\begin{array}{l}\text { Age of depth } \\
\text { interval (Ma) }\end{array}$} & \multirow[b]{2}{*}{$\begin{array}{l}\text { Depth interval } \\
\text { (mbsf) }\end{array}$} & \multirow[b]{2}{*}{$\begin{array}{l}\text { Mean depth } \\
\text { (mbsf) }\end{array}$} & \multicolumn{2}{|c|}{ Calcium yield } \\
\hline & & & $\begin{array}{l}\text { Spectral } \\
\text { peak } \\
\text { location } \\
\text { (m) }\end{array}$ & $\begin{array}{l}\text { Period } \\
(1000 \mathrm{yr})\end{array}$ \\
\hline $2.423-3.340$ & $163.85-182.90$ & 173.37 & 5.30 & 227.30 \\
\hline $2.478-3.342$ & $166.25-185.30$ & 175.77 & 6.68 & 302.97 \\
\hline $2.482-3.442$ & $168.65-187.70$ & 178.17 & 6.98 & 351.75 \\
\hline $2.623-3.540$ & $171.05-190.10$ & 180.57 & 6.98 & 335.99 \\
\hline $2.764-3.636$ & $173.45-192.50$ & 182.97 & 7.31 & 334.61 \\
\hline $2.905-3.733$ & $175.85-194.90$ & 185.37 & 8.53 & 370.75 \\
\hline $3.021-3.830$ & $178.25-197.30$ & 187.77 & 8.08 & 343.61 \\
\hline $3.145-3.910$ & $180.65-199.70$ & 190.17 & 7.68 & 308.41 \\
\hline $3.246-3.979$ & $183.05-202.10$ & 192.57 & 8.08 & 310.90 \\
\hline $3.349-4.107$ & $185.45-204.50$ & 194.97 & 7.68 & 305.59 \\
\hline $3.448-4.161$ & $187.85-206.90$ & 197.37 & 7.68 & 287.45 \\
\hline $3.545-4.216$ & $190.25-209.30$ & 199.77 & 7.68 & 270.51 \\
\hline $3.642-4.371$ & $192.65-211.70$ & 202.17 & 7.31 & 279.74 \\
\hline
\end{tabular}

deposition (bioturbation, compaction, and chemical dissolution) may alter a subtle original geological signal. This may partly explain the lack of correlation of the observed periods within interval $\mathrm{C}$ with any of the Milankovitch cycles. Another parameter that has not been discussed is the quality of the geochemical data. These data were acquired through only a single logging run through the drill pipe, which makes evaluation of the quality of the geochemical data difficult. At present, they should be inter- preted in a fairly qualitative sense as an indicator of the variations in percent carbonate. There is a reasonable correlation between the laboratory-determined percent carbonate data and the Ca yield data (Froelich et al., this volume).

The presentation of the spectra of logging data as depthperiod-amplitude spectrograms provides information on the changes in spectral characteristics with depth that may be interpreted to reflect changes in lithology, accumulation rates, diagenesis, and hiatuses related to periods of erosion or nondeposition. This information is lost when the spectra of the entire record length are presented. The FFT-generated spectrograms may therefore prove to be an important aid in the analysis and display of logging data.

\section{ACKNOWLEDGMENTS}

The authors wish thank Drs. R. Jarrad and L. Mansinha for their comments on the spectral analysis of logging data. This is Geological Survey of Canada Contribution no. 10489.

\section{REFERENCES}

Briskin, M., and Harrell, J., 1980. Time-series analysis of the Pleistocene deep-sea paleoclimatic record. Mar. Geol., 36:1-22.

Ciesielski, P. F., Kristoffersen, Y., et al., 1988. Proc. ODP, Init. Repts., 114: College Station, TX (Ocean Drilling Program).

Harris, F. J., 1978. On the use of windows for harmonic analysis with the discrete Fourier transform. Proc. IEEE, 66:51-83.

Hays, J. D., Imbrie, J., and Shackleton, N. J., 1976. Astronomical theory of ice ages confirmed. Science, 194:1121-1132.

Hodell, D. A., Ciesielski, P. F., and Mead, G. A., in press. Interhemispheric comparison of oceanographic changes between the Southern Ocean and the Northern Hemisphere during the Matuyama Chron (2.47 to $0.97 \mathrm{Ma}$ ). Int. Geol. Congr., 28th. (Abstract)

Imbrie, J., and Imbrie, J. Z., 1980. Modeling the climatic response to orbital variations. Science, 207:943-953. 
Moore, T. C., Pisias, N. G., and Dunn, D. A., 1982. Carbonate time series of the Quaternary and late Miocene sediments in the Pacific Ocean: spectral comparison. Mar. Geol., 46:217-233.

Morley, J. J., and Shackleton, N. J., 1984. The effect of accumulation rate on the spectrum of geologic time series: evidence from two South Atlantic sediment cores. In Berger, A., Imbrie, J., Hays, J., Kukla, G., and Saltzman, B. (Eds.), Milankovitch and Climate: Holland (Reidel), 467-480.

Oppenheim, A. V., 1970. Speech spectrograms using the fast Fourier transform. IEEE Spectrum, AU-7:57-62.

Park, J., and Herbert, T. D., 1987. Hunting for paleoclimatic periodicities in a geologic time series with an uncertain time scale. $J$. Geophys. Res., 92:14027-14040.

Park, J., Lindberg, C. R., and Vernon, F. L., III, 1987. Multitaper spectral analysis of high-frequency seismograms. J. Geophys. Res., 92:12675-12684.

Pestiaux, P., and Berger, A., 1984. An optimal approach to the spectral characteristics of the deep-sea climatic records. In Berger, A., Imbrie, J., Hays, J., Kukla, G., and Saltzman, B. (Eds.), Milankovitch and Climate: Holland (Reidel), 417-445.

Pisias, N. G., and Moore, T. C., 1981. The evolution of the Pleistocene: a time series approach. Earth Planet. Sci. Lett., 52:450 458.

Ruddiman, W. F., Raymo, M., and McIntyre, A., 1986. Matuyama 41,000-year cycles: North Atlantic Ocean and Northern Hemisphere ice sheets. Earth Planet. Sci. Lett., 80:117-129.
Schiffelbein, P., and Dorman, L., 1986. Spectral effects of time-depth nonlinearities in deep sea sediments records: a demodulation technique for realigning time depth scales. J. Geophys. Res., 91:3821-3835.

Shackleton, N. J., and Opdyke, N. D., 1976. Oxygen-isotope and paleomagnetic stratigraphy of Pacific Core V28-239: late Pliocene to latest Pleistocene. In Cline, R. M., and Hays, J. D. (Eds.), Investigation of Late Quaternary Paleoceanography and Paleoclimatology: Mem. Geol. Soc. Am., 145:449-464.

Volat, J.-L., Pastouret, L., and Vergnaud-Grazzani, C., 1980. Dissolution and carbonate fluctuations in Pleistocene deep-sea cores: a review. Mar. Geol., 34:1-28.

Welch, P. D., 1967. The use of fast Fourier transform for the estimation of power spectra: a method based on time averaging over short, modified periodograms. IEEE Trans. Audio Electroacoust., AU-15:70-74.

Date of initial receipt: 4 April 1989

Date of acceptance: 12 December 1989

Ms 114B-166 